\title{
Strategies for the selection of oncoplastic techniques in the treatment of early-stage breast cancer patients
}

\author{
Shengchao Huang, Pu Qiu, Jianwen Li, Zhongzeng Liang, Zeming Yan, Kangwei Luo, Baoyi Huang, \\ Liyan Yu, Weizhang Chen, Yuanqi Zhang \\ Department of Breast Surgery, Affiliated Hospital of Guangdong Medical University, Zhanjiang, China \\ Contributions: (I) Conception and design: Y Zhang; (II) Administrative support: J Li; (III) Provision of study materials or patients: S Huang, P Qiu; (IV) \\ Collection and assembly of data: Z Liang, Z Yan, K Luo; (V) Data analysis and interpretation: B Huang, L Yu, W Chen; (VI) Manuscript writing: All \\ authors; (VII) Final approval of manuscript: All authors. \\ Correspondence to: Yuanqi Zhang. Department of Breast Surgery, Affiliated Hospital of Guangdong Medical University, Zhanjiang 524001, China. \\ Email: 31428319@qq.com.
}

\begin{abstract}
Backgroundz In recent years, breast cancer is the most common malignancy in women. The traditional method of surgery is to remove a woman's breast completely, which has a negative impact on her work and life. Today, women have a fiery pursuit to maintain their perfect figure, which has forced breast surgeon to find a new surgical approach to maintain the shape of the breast after surgery.

Methods: This study systematically analyzed and summarized the incision design and repair of glandular defects in early-stage breast cancer patients by oncoplastic breast techniques. By summarizing the methods of oncoplastic breast surgery (OBS) in different quadrants, it could help beginners to master this technology more quickly, so as to provide better help for breast cancer patients.

Results: A total of 216 breast cancer patients who underwent OBS from January 2016 to June 2020 at the Affiliated Hospital of Guangdong Medical University were included in this study. In patients treated with the volume-displacement method and the volume-replacement method, $92.6 \%$ and $86.2 \%$ of patients achieved excellent breast shape, respectively.
\end{abstract}

Conclusions: OBS is a safe and effective way to treat early-stage breast cancer while obtaining better breast shape, reducing postoperative psychological trauma, and improving quality of life.

Keywords: Oncoplastic techniques; early-stage; breast cancer

Submitted Mar 10, 2021. Accepted for publication Apr 29, 2021.

doi: $10.21037 / g s-21-212$

View this article at: http://dx.doi.org/10.21037/gs-21-212

\section{Introduction}

Breast cancer is a highly prevalent female malignancy in China, affecting approximately 280,000 women annually. Breast cancer occurs most commonly in women aged $45-55$ years and thus, has a serious impact on a woman's career and quality (1-3). With improvements in breast ultrasound examination by medical institutions, most breast tumors are detected in the early stages, and the 5 -year overall survival rate after standardized treatment exceeds $80 \%$ (4). Nowadays, breast cancer patients attached great importance to the aesthetic effect of the breast after surgery $(5,6)$.
Several studies have shown (7-10) no significant differences in overall survival, disease-free survival, local recurrence, distant metastasis rates, and overall efficacy between breast-conserving surgery and radical breast cancer treatment. However, studies have shown that approximately $20-30 \%$ of patients who underwent traditional breast conservation had poor cosmetic results due to the absorption of serum in the tumor cavity or postoperative radiotherapy, resulting in breast deformities $(11,12)$. In fact, some patients forgo breast conservation because they cannot obtain satisfactory cosmetic outcomes due to their small breast size, large tumor size, or tumor location restrictions. 
Oncoplastic breast surgery (OBS) is a novel approach to breast conservation surgery that combines the aesthetic concepts of plastic surgery with the radical concepts of oncological surgery. Unfortunately, lots of breast treatment centers do not promote this technique (13). The purpose of this study is to explore the selection of appropriate OBS techniques to repair the defects after breast tumor resection in different locations, including the choice of surgical incision and the use of nearby glands to repair the defects.

We present the following article in accordance with the STROBE reporting checklist (available at http://dx.doi. org/10.21037/gs-21-212).

\section{Methods}

\section{Patients}

This study was a retrospective analysis. All procedures performed in this study involving human participants were in accordance with the Declaration of Helsinki (as revised in 2013). The study was approved by regional ethics board of Affiliated Hospital of Guangdong Medical University (No.YS20201600) and informed consent was taken from all the patients.

Inclusion criteria:

(I) Age $\geq 18$ years old;

(II) Breast cancer was confirmed by preoperative pathology;

(III) The clinical stages were I and Anal;

(IV) Postoperative systematic treatment can be completed according to the doctor's advice;

(V) The patient was informed of the operation method and signed the consent form.

Exclusion criteria:

(I) patients with severe chronic heart and brain diseases;

(II) Patients with neurological or psychiatric diseases;

(III) Patients cannot cooperate to complete follow-up visits.

A total of 220 patients with early breast cancer who were treated at Affiliated Hospital of Guangdong Medical University from January 2016 to June 2020 were selected as the research objects. Among the enrolled patients, the oldest was 68 years old, the youngest was 28 years old, and the median age was 48.5 years old. According to the individual condition of the patient, the volume displacement method or volume replacement method is selected in the operation. Patients were followed up by two independent investigators.
Postoperative breast aesthetics was evaluated using Harris evaluation criteria. Two independent investigators collected patients' satisfaction with their breast one year after surgery

\section{Statistical analysis}

SPSS 18.0 was used for statistical analysis; enumeration data was represented by percentage $(\mathrm{N} / \%)$; Chi-square test was used, $\mathrm{P}<0.05$ indicated that the difference was statistically significant. Missing data were not included in the study.

\section{Incision design of $\mathrm{OBS}$}

The presence of a breast incision scar is one of the most important indicators to evaluate its aesthetics (14). The incision design should satisfy both radical removal of the cancerous tissue and concealment of the incision location. Prior to surgery, the incision site will be determined according to the tumor location and size, the position of the nipple areola, and the volume and sagging of the breast. In addition, the choice of incision has a great impact on the whole surgical process and postoperative breast beauty. Based on the OBS experience in our department, the following criteria were developed:

(I) If the tumor is close to the areola area and more than $2 \mathrm{~cm}$ from the nipple, but does not invade the nipple areola, a double circumferential incision can be adopted;

(II) If the tumor is located in the upper pole of the nipple-areola complex, an Omega incision or an inverted T-shaped incision can be made;

(III) If the tumor is located in the lower pole of the nipple-areola complex, an inframammary fold incision or an inverted T-shaped incision may be made;

If the tumor is located above the level of the nipple, a shuttle incision, parallelogram incision, or curved incision can be adopted. If the mass is close to the axillary position, Tan et al. (15) suggests a radial incision to extend to the axilla. In addition, lymph node biopsies or axillary lymph node dissections may be feasible while removing the cancerous tissue, after which the gland can be freed for repair;

If the tumor is located below the level of the nipple, the surgery can be performed with a J-shaped incision, an $\mathrm{L}$-shaped incision, or a $\mathrm{V}$-shaped incision;

If the tumor is located in the central region of the tumor, a shuttle incision including the nipple-areola complex can be designed, and reconstruction of the nipple-areola is 

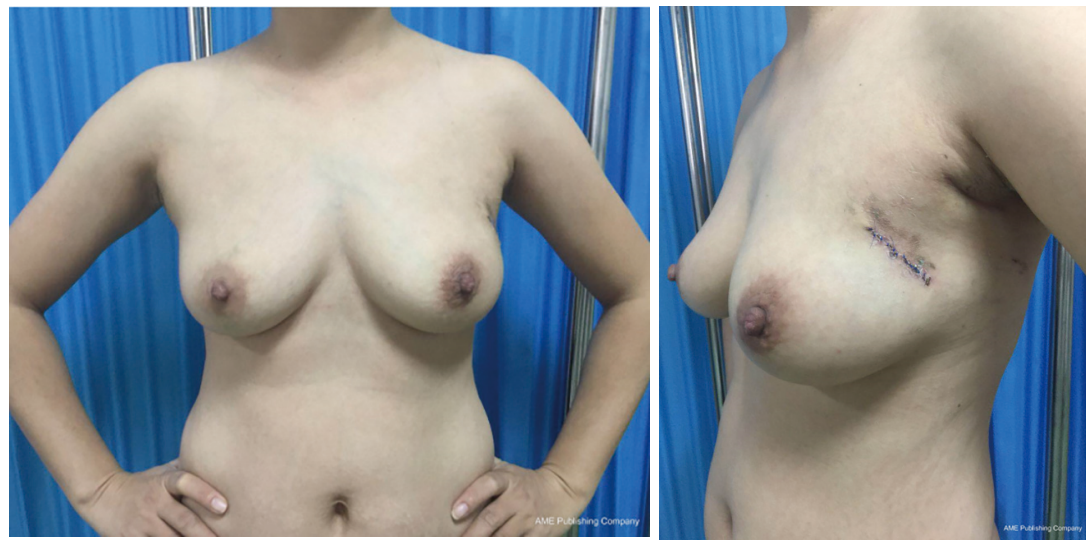

Figure 1 Breast defect repair by advancement of residual gland suture.

feasible at a later stage to ensure the aesthetics of the breast;

A tennis racket incision design may be used when the tumor is located lateral to the same level of the nipple;

To perform axillary lymph node dissection, a small arcshaped incision should be designed along the skin line in the axilla, while preserving as much axillary fat as possible to avoid affecting the postoperative axillary shape.

\section{Surgical techniques for the repair of breast defects in different quadrants}

Clough's classification criteria (16) is the most explicit: the proportion of the removed gland that takes up the entire breast can be divided into three levels: (I) when the resection volume is less than $20 \%$, it is classified as type I, and the residual cavity can be repaired by direct suturing of the residual breast tissue to repair the defect; (II) when the resection volume is $20-50 \%$, it is classified as type II, which requires more complex plastic surgery techniques to repair the residual cavity and shape; and (III) when the amount of excision is more than $50 \%$, it is classified as type III, which requires total mastectomy followed by reconstructive surgery with autologous breast tissue or artificial prosthesis. This study focused on residual cavity repair for glandular excision of $20-50 \%$, as the choice of repair method is often not clear to many breast surgeons.

\section{Glandular excision less than $\mathbf{2 0} \%$}

If the mass is small and the removal of a small amount of the gland has little effect on the postoperative breast appearance, a radial or curved incision can be made in the skin above the tumor. Surgeon can pull adjacent glands closer and sew them together to reshape the breast without the need for OBS techniques. However, some studies (17) indicate that because the volume of the removed gland is relatively small, not suturing the adjacent mammary gland may guarantee a satisfactory breast appearance. However, the long-term cosmetic benefits of this method have not been proven (Figure 1).

\section{Volume-displacement method}

The removal of up to $20-50 \%$ breast gland, along with the need to remove some of the skin, can cause significant deformities in the appearance of the breast. Restoring the appearance of the breast is a challenge for every breast surgeon. OBS can be divided into the volume-displacement method and the volume-replacement method. For glandular defects of $20-50 \%$, volumetric transfer is the most common method, and if volumetric transfer is not possible, then volumetric substitution is preferred.

\section{Racket-shape oncoplastic breast conservation method}

The racket-shape oncoplastic breast conservations method is suitable for tumors located at the same level of the nipple in the lateral and upper outer quadrant, mainly to avoid the nipple-areola complex from tilting outward and upward. A concentric incision is made at the edge of the areola and the epidermis is removed from the concentric circles. A shuttleshaped incision is then made along the breast mass to remove the tumor. The breast is reshaped into a semicircle by the assistant using both hands, while the surgeon frees the medial and lateral glands and pulls them together, and sutures them to fill the breast defect and complete the reconstruction of the breast shape. The surgeon then performs a re-centering of the nipple-areola complex (Figure 2).

\section{f-shape oncoplastic breast conservation method}

The J-shape oncoplastic breast conservation method is 

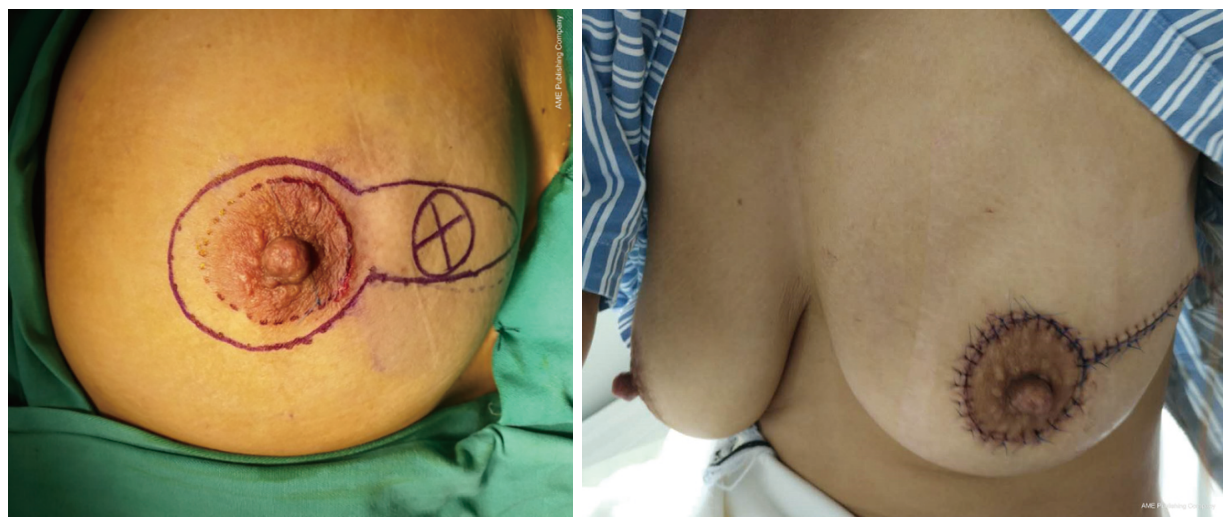

Figure 2 Racket-shape oncoplastic breast conservation method.

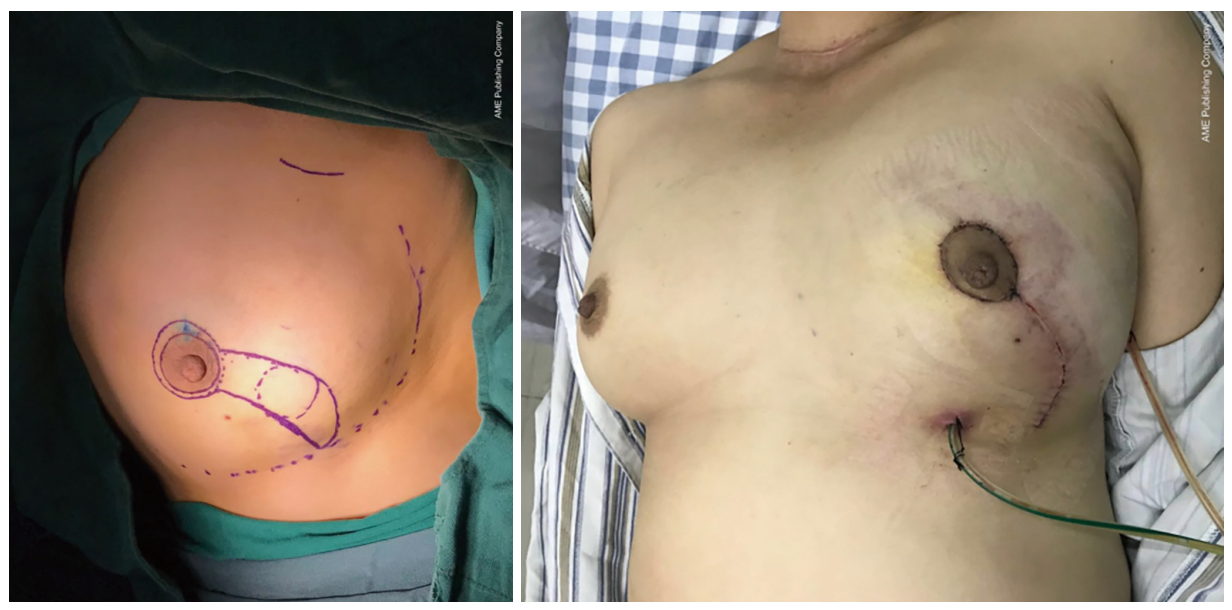

Figure $3 \mathrm{~J}$-shape oncoplastic breast conservation method.

suitable for tumors located below the level of the nipple. A concentric circular incision is made around the areola and the epidermis is removed. Curved incisions are made along the medial and lateral sides of the areolar incision and turned towards the inframammary fold. After removal of the mass, the surgeon frees the medial and lateral glands, sutures them together and then fills the breast defect to complete the glandular reconstruction. The nipple-areola complex is then recentered. This approach was pioneered by Lassus et al. in 1996 (18) and has the advantage of preventing deformities in the outer lower quadrant (Figure 3).

\section{Inverted T-shape oncoplastic breast conservation method}

The inverted T-shape oncoplastic breast conservation method is suitable for tumors located in the upper or lower pole of the nipple-areola complex with breast ptosis. The width and depth of the superior tip of the tumor is measured and a preoperative line is drawn, then the skin is cut and the epidermis of the superior tip is removed. On the premise of ensuring the blood supply to the nipple areola, the mass is removed intact, the medial and lateral glands are freed to form free glandular flaps and then the nipple areola is lifted and re-centered. Subsequently, the medial and lateral free glandular flaps are pulled together and sutured toward the midline of the inframammary fold to form the new inframammary fold of the breast. This method was first proposed by Clough et al. (19) in 1990 and has the advantage of preventing a "beak-like" deformity of the breast due to skin wrinkling and downward displacement of the nipple-areola complex (Figure 4).

\section{Z-shape oncoplastic breast conservation method}

The Z-shape oncoplastic breast conservation method is suitable for tumors located at 6 o'clock with flattened or 

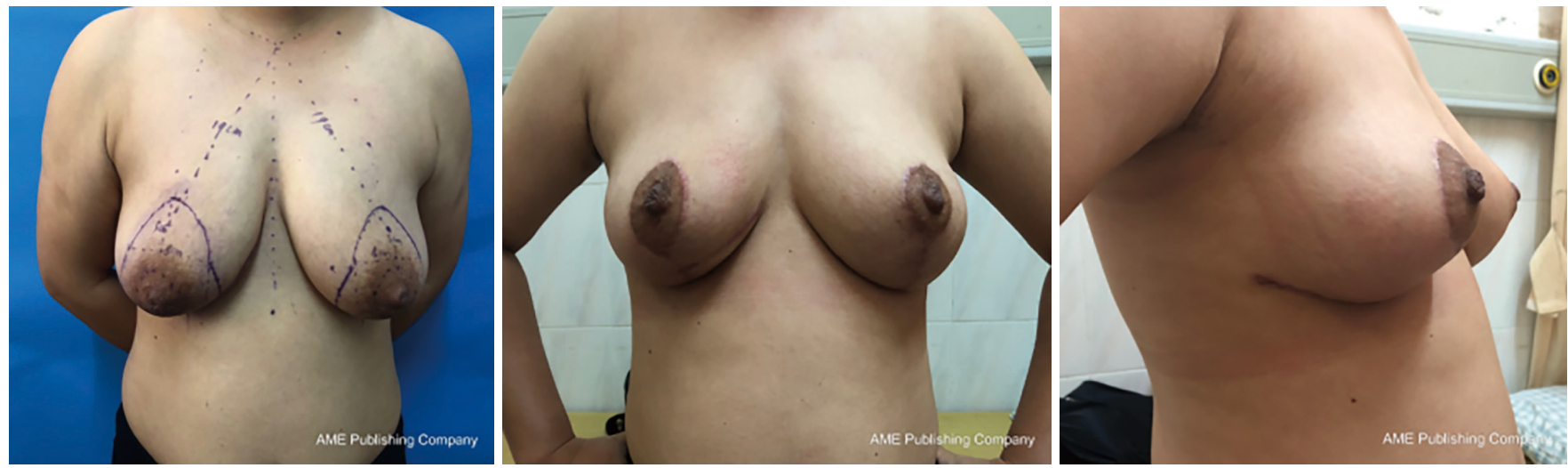

Figure 4 Inverted T-shape oncoplastic breast conservation method.
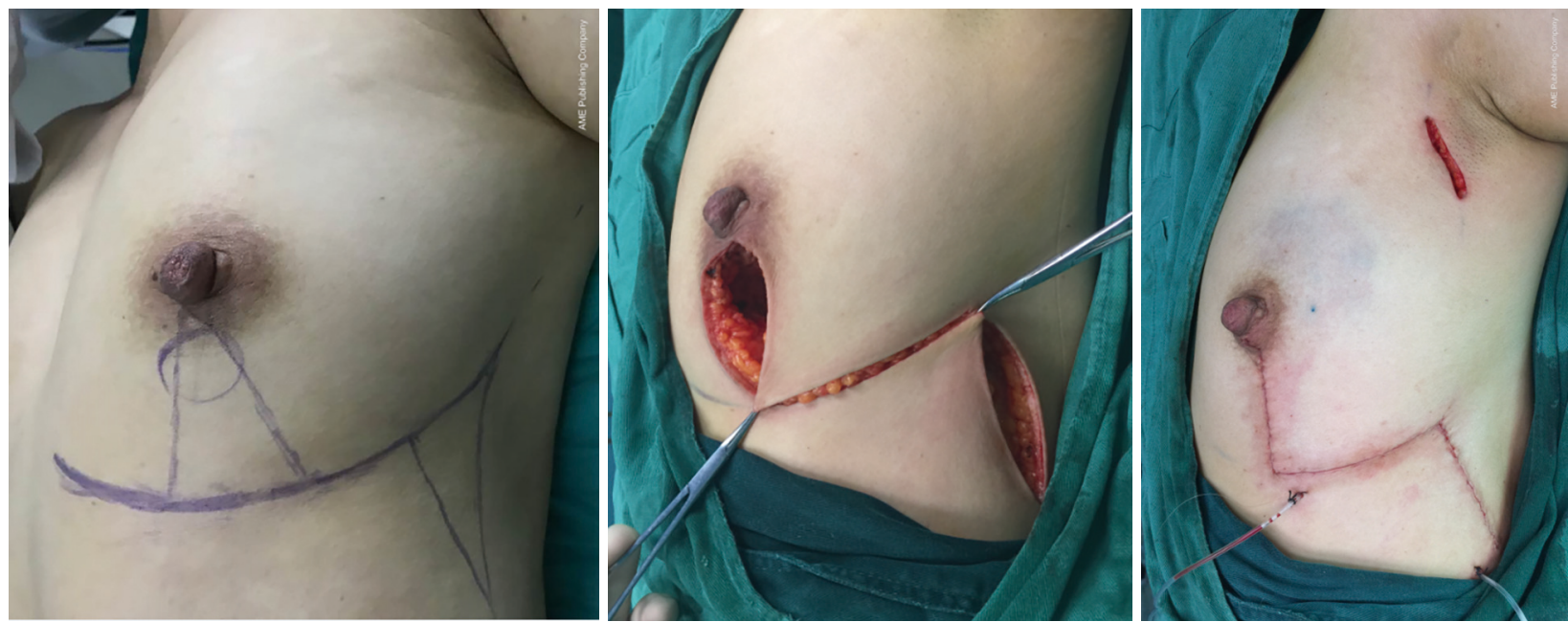

Figure $5 \mathrm{Z}$-shape oncoplastic breast conservation method.

mildly sagging breasts (Figure 5).

\section{A-T-shape oncoplastic breast conservation method}

The A-T shape oncoplastic breast conservation method is suitable for plastic breast conservation in cases where the tumor is located in the lower or outer lower quadrant of the breast (Figure 6).

\section{Omega-shape oncoplastic breast conservation method}

The omega-shape oncoplastic breast conservation method is suitable when the tumor is located in the upper pole of the nipple-areola complex. A located in the upper pole of the nipple-areola comla to excise part of the skin, the breast tumor, and the surrounding normal glandular tissue. The glandular tissue below is then freed, the free glandular body is lifted and the breast defect is repaired with parallel sutures. The nipple areola complex is then lifted and recenter. In 2005, Anderson and colleagues were the first to report (20) an omega-shape breast-conserving procedure, with the main advantage of lifting the gland below the tumor to repair the upper pole of the defect, thereby improving the postoperative sagging of the breast (Figure 7). Double ring-shape oncoplastic breast conservation method The double ring-shape oncoplastic breast conservation method is suitable for tumors located next to the areola with mild sagging of the breast. A circular incision is made along the areola, another circular incision is made outside the circular incision according to the size and location of the tumor, the position of the nipple, and the degree of breast ptosis. The inter-ring epidermis is removed, the gland surface at the outer ring is fully freed, and the soft tissue in the area where the tumor is 

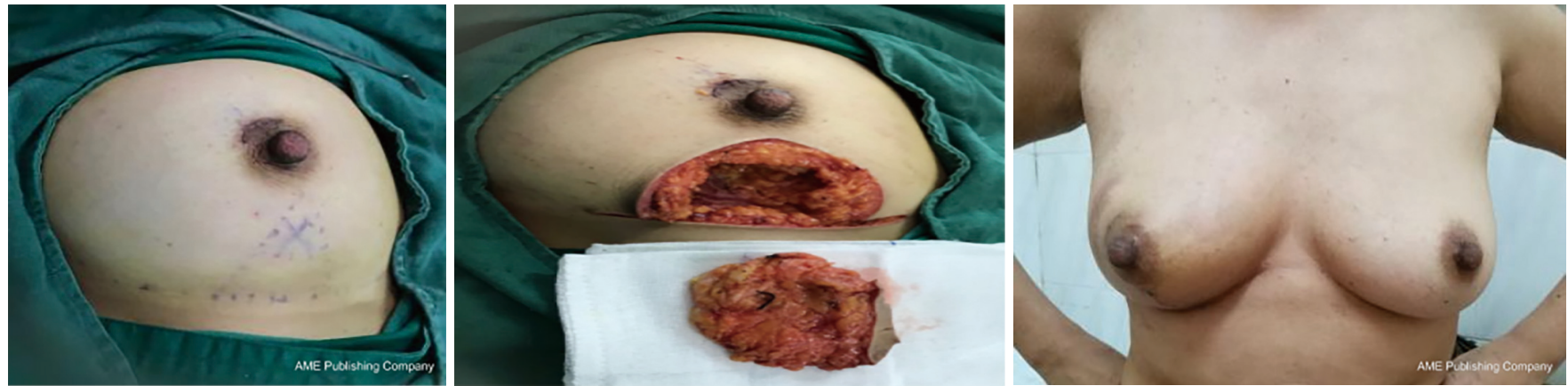

Figure 6 A-T-shape oncoplastic breast conservation method.
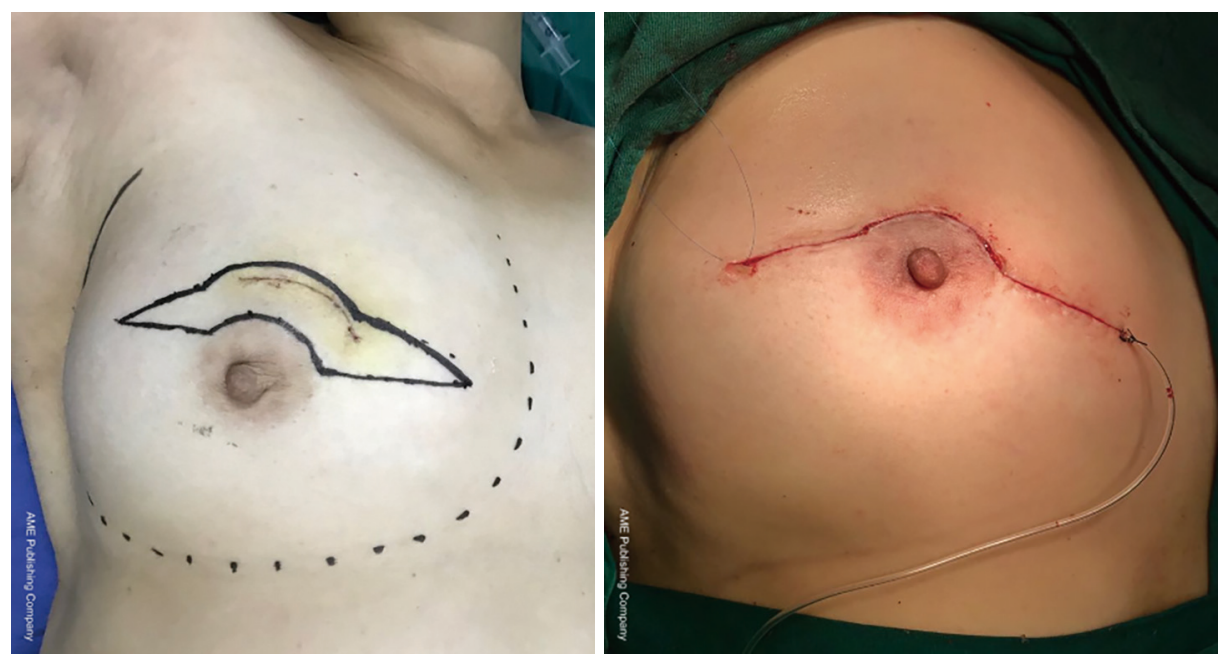

Figure 7 Omega-shape oncoplastic breast conservation method.

located is excised in its entirety. Then, the medial and lateral glands are pulled together and intermittently sutured to repair the defect and reshape the breast, followed by centralization of the nipple-areola complex. This method was first reported by Benelli in 1990 (21) and has the main advantage of preventing displacement of the nipple-areola complex (Figure 8).

\section{V-shape oncoplastic breast conservation method}

When the tumor is located below the level of the nipple, especially in the lower inner quadrant, the $\mathrm{V}$-shape oncoplastic breast conservation method is performed. A circular incision is made at the edge of the areola and the epidermis is removed along the incision, followed by a triangular incision including the mass (the intersecting point of the incision is located at the edge of the areola and the lower boundary of the incision is located at the breast fold). After complete excision of the mass, the lateral glandular flap is freed, pulled inward and sutured to repair the inframammary fold to complete the glandular reconstruction, followed by centralization of the nippleareola complex (Figure 9).

\section{Arbitrary flap method}

When flatter breasts are accompanied by skin invasion, the arbitrary flap method can be used for breast defect repair (Figure 10).

\section{Volume replacement method}

According to the Chinese Expert Consensus on Treatment of Breast Conservation (2020 version) (22), volumereplacement techniques, mainly adjacent flap transfer and distal flap transfer, are recommended when local soft tissue repair or free adjacent gland repair after mastectomy of the cancer site would create a deformity such as breast depression. 

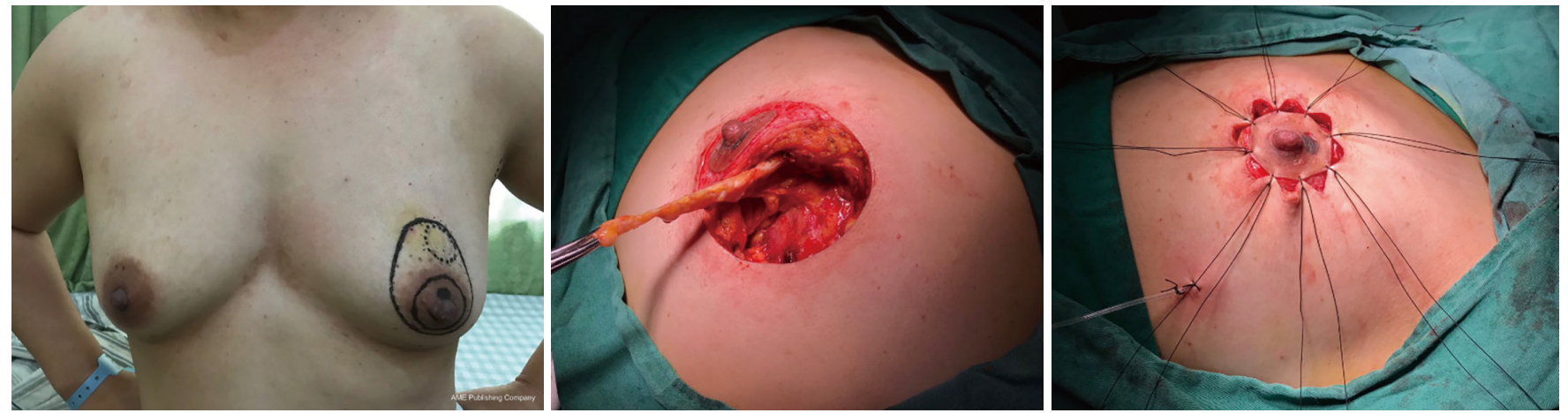

Figure 8 Double ring-shape oncoplastic breast conservation method.
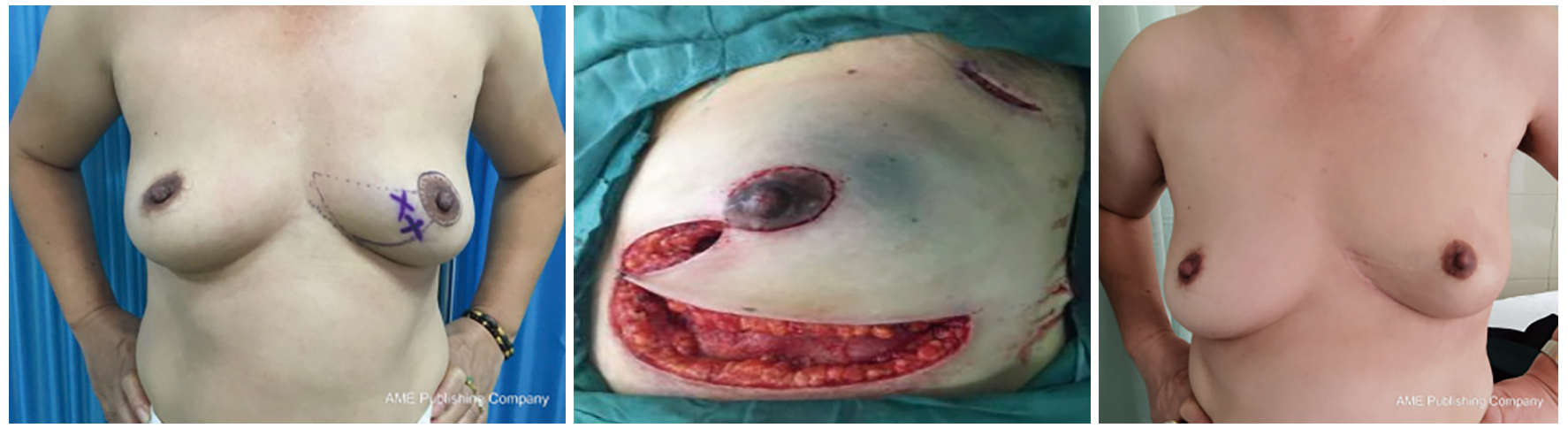

Figure $9 \mathrm{~V}$-shape oncoplastic breast conservation method.
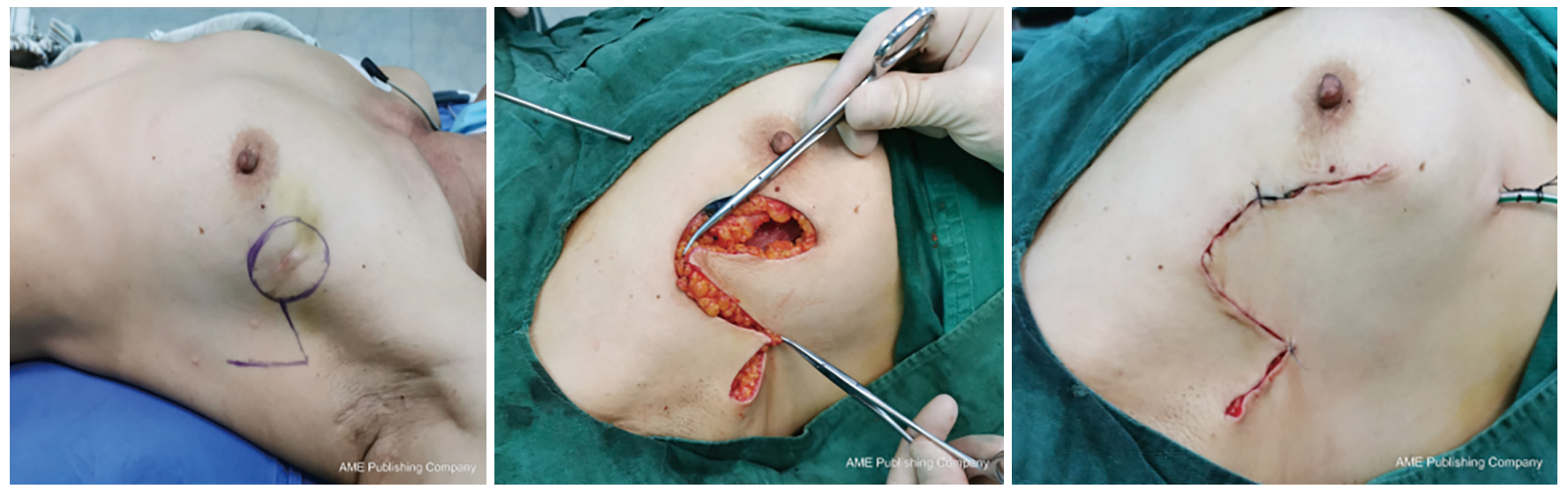

Figure 10 Arbitrary flap method.

\section{Application of lateral thoracic vascular perforator flap}

Lateral thoracic vascular perforator flap, intercostal vascular perforator flap, and dorsal thoracic vascular perforator flap can be used for repair of larger defects after mastectomy. These flaps are particularly suitable for plastic repair where the tumor is located laterally and superiorly, but only for repair of smaller breast defects (Figure 11).

\section{Application of the greater mentum}

The large omentum is rich in blood vessels and lymphatic vessels, and its rich blood flow gives rise to its strong 

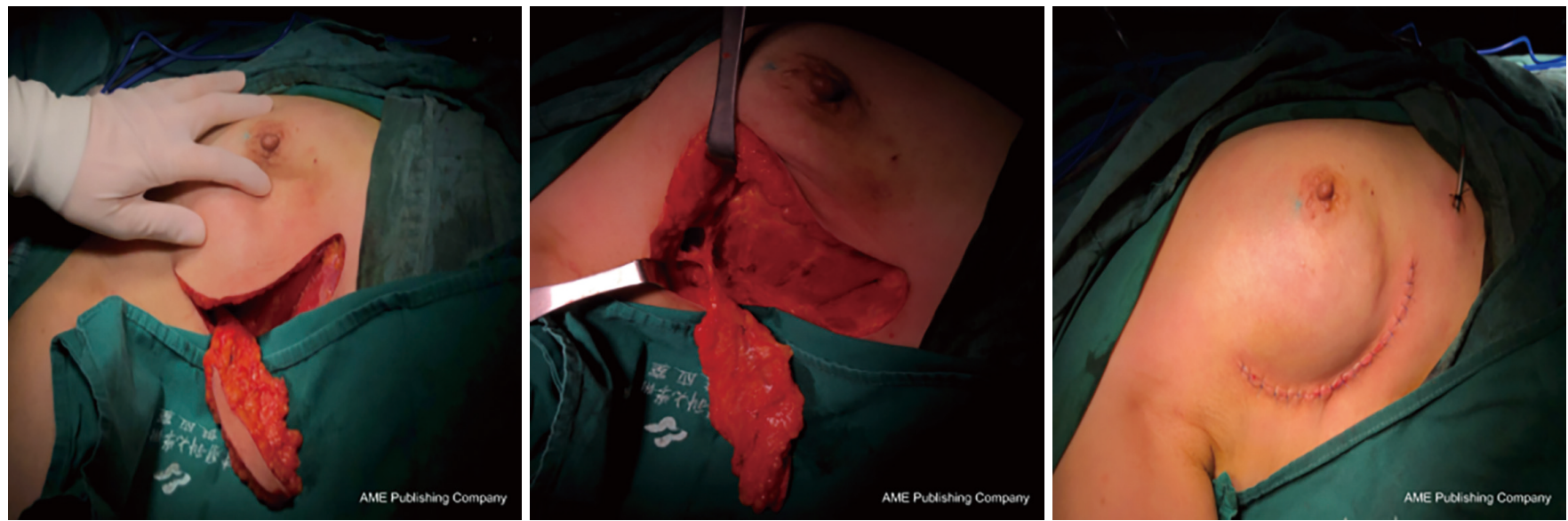

Figure 11 Application of lateral thoracic vascular perforator flap.

absorption and anti-inflammatory function, which can reduce the incidence of subcutaneous seroma, and result in a soft enough feel and fast postoperative recovery. However, due to its limited tissue volume, it is not suitable for repair of larger breasts (Figure 12).

\section{Application of the mini-tipped latissimus dorsi flap}

The anatomical position of the thoracodorsal artery of the latissimus dorsi flap is constant, which has the advantages of a long vascular tip, thick vascular tip caliber, and high flap viability. In addition, the latissimus dorsi flap can be cut with a wide flap area, and the donor area can be directly pulled together and sutured, resulting in little influence on upper limb function. Furthermore, it can be used for breast defect repair in any quadrant and is most commonly used for breast repair with large defects (Figure 13).

\section{Results}

A total of 220 patients who underwent oncoplastic breast treatment from January 2016 to June 2020 at the Affiliated Hospital of Guangdong Medical University were included in this study. Within the study cohort, 140 patients were treated with the volume-displacement method (group A) and 80 patients received the volume-replacement method (group B). The median age of the cohort was 48.5 years, with a range of 28-68 years. All surgeries were performed by the same surgical team. Patients with positive margins required a second expansion surgery to obtain negative margins. No contralateral breast symmetry surgery was performed in patients in either group. Their postoperative diagnosis confirmed early breast cancer. All patients were followed up for 1 year postoperatively for breast satisfaction by two independent investigators. The location, shape, size, and symmetry of the breasts were assessed using the Harris evaluation criteria (23). The satisfaction rate of postoperative breast aesthetics was $90.9 \%$ in group A and $89.3 \%$ in group B after 1 year, suggesting that there was little difference between two methods. Eight patients in Group A and 5 patients in Group B were lost to follow-up .The final follow-up rate was 132/140 (94.3\%) for Group A and 75/80 (93.8\%) for Group B. There was no statistical difference between the two groups $\left(\chi^{2}=0.136, \mathrm{P}=0.712\right)$. And missing follow-up data were not included in the satisfaction statistics (Table 1).

\section{Discussion}

Currently, Breast cancer harms women seriously and has a high incidence in the world. On the one hand, women's menarche time, lactation and endocrine disorders and other problems will cause abnormal metabolism in the body, thus leading to the occurrence of breast cancer. On the other hand, heredity is a high risk factor for breast cancer. Breast cancer has a genetic susceptibility problem, which is very obvious among family sisters, mother and daughter. In addition, smoking, drinking and other bad habits will cause damage to the body's various functions, can induce the occurrence of breast cancer. Surgical treatment of breast cancer has always been a hot research topic

In 1993, the German surgeon Dr. Audretsch officially introduced the term "oncoplastic surgery", which is derived from the Greek words "onco" (tumor) and "plastic" (plastic) (24). It is essentially a plastic surgery procedure that ensures the best cosmetic outcome while ensuring 

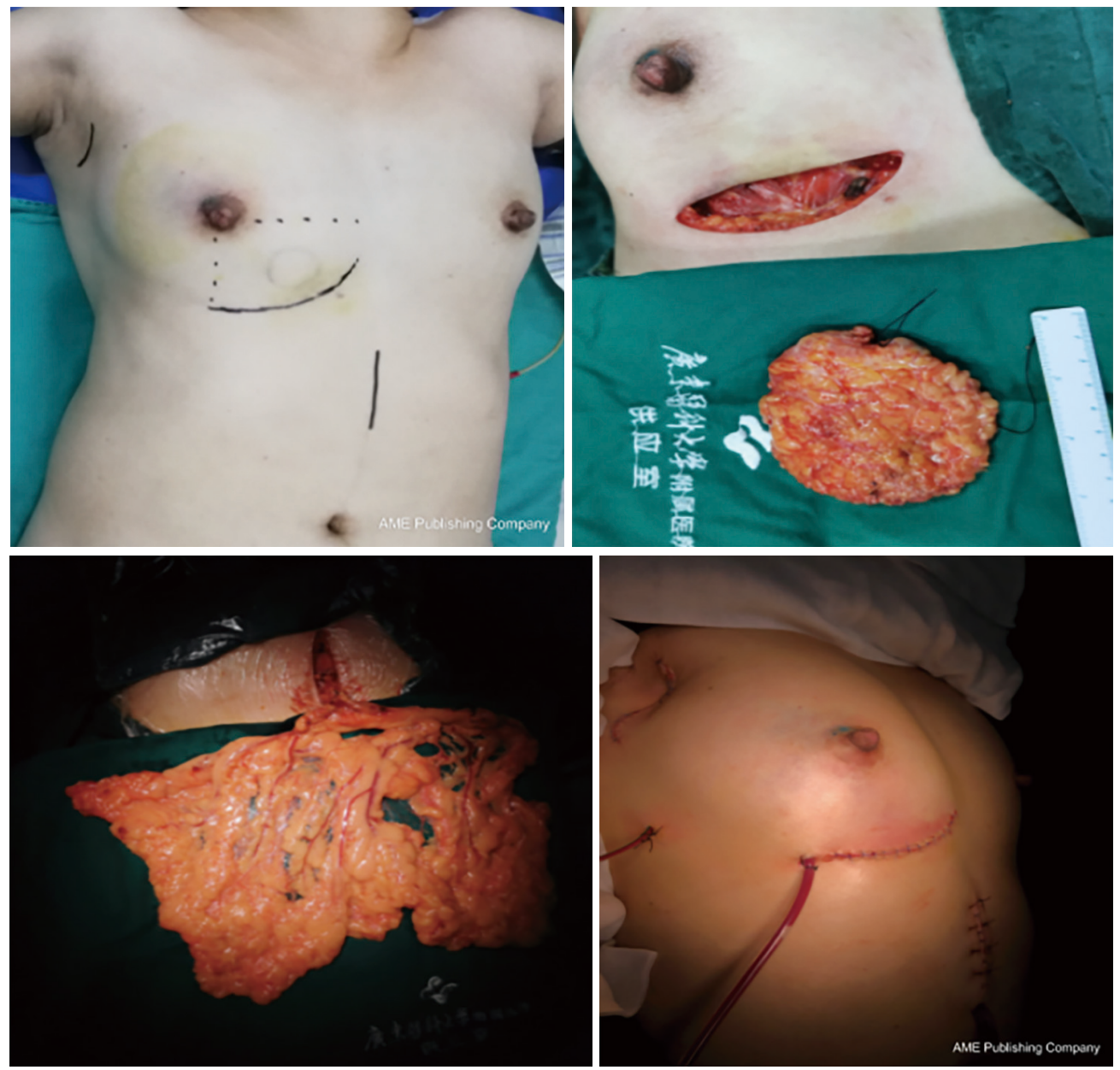

Figure 12 Application of the greater mentum.
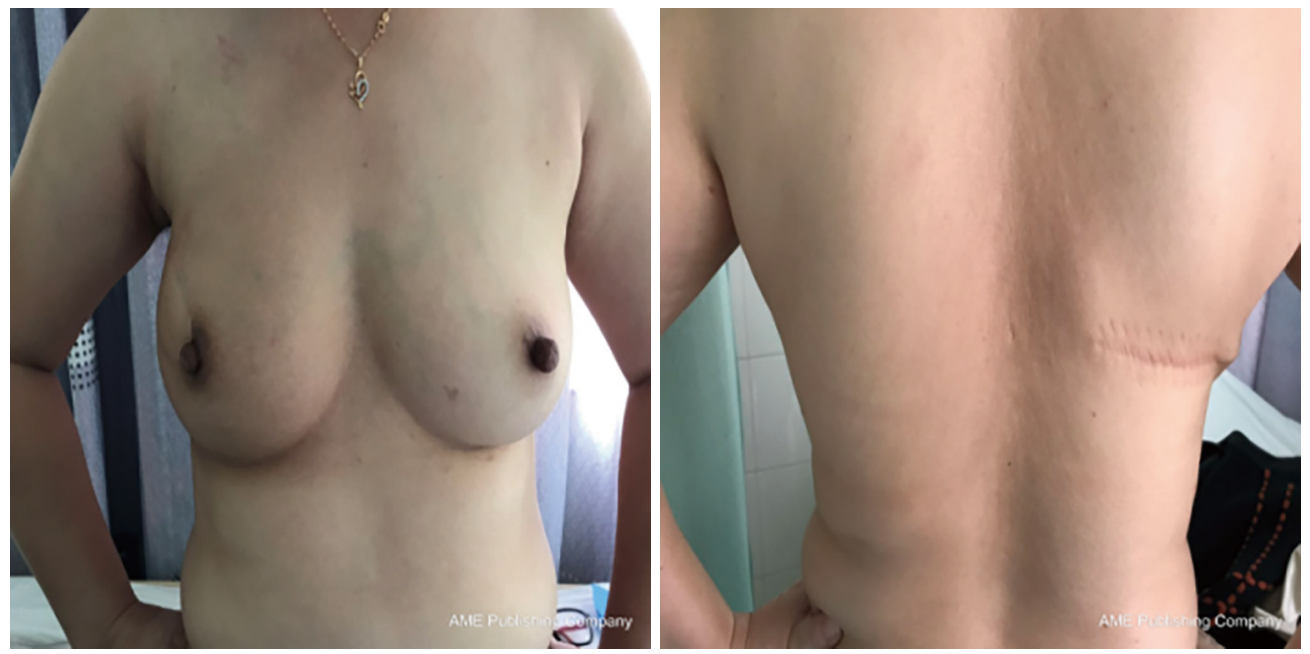

Figure 13 Application of the mini-tipped latissimus dorsi flap. 
Table 1 Postoperative patient satisfaction with aesthetics

\begin{tabular}{lccccc}
\hline Group & Excellent (\%) & Good (\%) & Discontent (\%) & Satisfaction rate (\%) & $\chi^{2}$ \\
\hline Group A & $106(80.3)$ & $14(10.6)$ & $12(9.1)$ & 90.9 & 0.136 \\
Group B & $58(77.3)$ & $9(12.0)$ & $8(10.7)$ & 89.3 & 0.712 \\
\hline
\end{tabular}

Group A includes patients who were treated with the volume-displacement method. Group B includes patients who were treated with the volume-replacement method.

radical removal of the tumor. This method quickly became popular in many countries including France, Italy, and the United Kingdom, where the rate of plastic surgery for breast tumors increased from $40 \%$ in 1991 to $60 \%$ in 2002 , and this rate continues to rise (25). In 2005, Zhang and Shao (26) reported 872 cases of breast cancer patients who underwent OBS. An aesthetic satisfaction rate of $91.1 \%$ at 1 year and $86.6 \%$ at 2 years after surgery was achieved. n 2015, Xuanwu Hospital of Capital Medical University reported that 10 patients received OBS, 8 of them were very satisfied with the breast shape after surgery, and 2 of them were satisfied with the breast shape after surgery (27). Similarly, a study of Dalian University School of Medicine reported that the satisfaction of 29 patients with early breast cancer who underwent breast tumor plastic surgery was $75.9 \%(22 / 29)(28)$.

In 2013, relevant data from several clinical research centers showed (29) that the 5 -year overall survival rate after OBS was $92.5-95.7 \%$, and the 5-year local recurrence rate was $0-9.4 \%$, while the local recurrence rate of traditional breast-conserving surgery was $10-14 \%$. Results of NSABP-06 clinical study showed (30) that there was no Statistical difference in DFS and OS between patients receiving breast conserving surgery and radical mastectomy (36.0\% vs. $35.0 \%, \mathrm{P}=0.26 ; 47.0 \%$ vs. $46.0 \%, \mathrm{P}=0.57$ ). The EORTC10801 clinical study (31) compared the efficacy of modified radical surgery and breast-conserving surgery combined with radiotherapy in patients with early-stage breast cancer (regardless of axillary lymph node condition). Patients treated with modified radical surgery had a better 10 -year local control rate, but the difference in OS rate between the two groups was not statistical difference (46.0\% vs. $39.0 \%, \mathrm{P}=0.23$ ). Losken published the results of a meta-analysis of OBS techniques (32): compared with traditional breast conserving, OBS had a lower margin positive rate ( $12 \%$ vs. $21 \%$ ), a lower re-excision rate ( $4 \%$ vs. $14.6 \%)$, and a lower local recurrence rate ( $4 \%$ vs. $7 \%$ ) due to the removal of more surrounding tissue.

In China, modified radical surgery and traditional breast- conserving surgery are the two mainstream modalities for the treatment of patients with breast cancer (33). The former results in the absence of the female breast due to the removal of all glandular tissues. In the latter approach, too much normal glandular tissue may be removed in order to reduce local recurrence of the tumor. This may lead to nipple displacement, local breast depression, breast deformation, and bilateral breast asymmetry, resulting in breast deformity and seriously affecting postoperative cosmetic outcomes. Importantly, both breast loss and deformity can result in psychological barriers, social barriers, and career barriers for female patients $(34,35)$, and cause both physical and mental strain $(36,37)$. Therefore, it is imperative to develop plastic surgery concepts and techniques to improve postoperative cosmetic breast outcomes during breast cancer conserving surgery to improve the quality of life of these patients. There are many factors affecting the aesthetic effect of breast, including the size and location of the tumor, the size and density of the breast, the ratio of the tumor's volume of the breast, whether the breast droops, the concealment of the incision and others. Therefore, we need to take all of these factors into account when we design the incision for OBS. In addition, major complications of OBS include bleeding, subcutaneous effusion, delayed wound healing, infection, seroma, adipose necrosis, and flap necrosis. Subcutaneous effusion is the most common complication, but it is selflimited and does not require additional treatment.

The indications for OBS are more extensive than for traditional breast conserving. It is mainly suitable for breast cancer with large tumor volume, multifocal tumor, skin invasion and tumor located in the lower pole and inner region, which is easy to cause deformity. The goals of OBS include complete removal of the lesion, clean incision margins, good to excellent cosmetic results, and completing all steps in one surgery. The key to the success of OBS is achieving negative surgical margins. The range of safe tumor excision of normal glandular tissue varies from a few millimeters to $2-3 \mathrm{~cm}$, but the exact standard 
value is still controversial. The guidelines of the American Society of Surgical Oncology and the American Society of Radiation Oncology (38) regarded "no ink on tumor" as the standard for breast-conserving surgery, however, it was more difficult to operate in practice. According to our clinical experience, to achieve a safe range of tumor excision, the tumor and the surrounding $1.5-2.0 \mathrm{~cm}$ of normal gland should be removed. Furthermore, the upper, lower, anterior, posterior, medial, and lateral margins should be sent for frozen pathology to confirm the presence or absence of cancer cells. If any of the margins appear positive, the resection should be expanded until the margins are negative. The American Society of Breast Surgeons (ASBS) defines oncoplastic techniques as complete excision of the breast tumor under the principle of anaplasia with the use of plastic techniques such as glandular flap transfer and myocutaneous flap transfer to achieve optimal aesthetic results in the breast (39). In addition, selecting the optimal OBS method based on the assessment of the volume of the breast and the location of the tumor is the key to ensuring the cosmetology of the breast post-surgery.

Although no statistical analyses of postoperative complications were conducted in this study, the above results demonstrated that there was no significant difference in the cosmetic effect between the volume-displacement method and the volume-replacement method. Therefore, OBS technology is suitable for promotion and application in patients with early-stage breast cancer. In the later stage, we will increase the number of patient samples and summarize the incidence of related complications to further verify the conclusion.

OBS is a superior method for the treatment of patients with clinical stage I and II breast cancer, because it avoids total mastectomy and guarantees a thorough radical tumor treatment and postoperative cosmetic breast effect (40). In 2014, a study (41) compared and analyzed the postoperative cosmetic effects of OBS and non-OBS in patients with early breast cancer. The excellent and good rate of breast cosmetic effect evaluation in OBS group was $86.8 \%$, while that in non-OBS group was $67.2 \%$. The total satisfaction rate of OBS group was $92.5 \%$ (62/67), and that of non-OBS group was $80.2 \%(93 / 116)$. The difference between the two groups was statistically significant $(\mathrm{P}<0.01)$. Moreover, report (42) has shown that, compared with modified radical surgery, OBS has a significant relieving effect on postoperative depression, and OBS has a very important positive impact on postoperative self-esteem of patients.
In traditional surgical procedures, women who underwent mastectomies perceive themselves as incomplete. What's more, women's sense of self-identity plummeted in response to the side effects of chemotherapy. As a result, they will have less contact with the outside world, and even have suicidal thoughts.

In recent years, a European data on early-stage breast cancer shows (43) that more than 78 percent of breast conservation treatments are available in Europe and the United States. The breast-conserving rate in Asia is generally lower than that in Europe and the United States, but recently, the breast-conserving rate in Japan, Singapore and Hong Kong of China has all exceeded $40 \%$ (44-46). But in China, the breast-conserving rate in more than half of hospitals was less than $20 \%$ (47). In addition, the breastconserving rate is related to the per capita GDP of the area where the hospital is located.

\section{Conclusions}

In conclusion, OBS is a superior treatment modality for early-stage breast cancer because it can remove the cancer lesion while obtaining satisfactory breast shape, reduce postoperative psychological trauma, and improve the quality of life for patients.

\section{Acknowledgments}

Funding: None.

\section{Footnote}

Reporting Checklist: The authors have completed the STROBE reporting checklist. Available at http://dx.doi. org/10.21037/gs-21-212

Data Sharing Statement: Available at http://dx.doi. org/10.21037/gs-21-212

Conflicts of Interest: All authors have completed the ICMJE uniform disclosure form (available at http://dx.doi. org/10.21037/gs-21-212). The authors have no conflicts of interest to declare.

Ethical Statement: The authors are accountable for all aspects of the work in ensuring that questions related to the accuracy or integrity of any part of the work are 
appropriately investigated and resolved. All procedures performed in this study involving human participants were in accordance with the Declaration of Helsinki (as revised in 2013). The study was approved by regional ethics board of Affiliated Hospital of Guangdong Medical University (No.YS20201600) and informed consent was taken from all the patients.

Open Access Statement: This is an Open Access article distributed in accordance with the Creative Commons Attribution-NonCommercial-NoDerivs 4.0 International License (CC BY-NC-ND 4.0), which permits the noncommercial replication and distribution of the article with the strict proviso that no changes or edits are made and the original work is properly cited (including links to both the formal publication through the relevant DOI and the license). See: https://creativecommons.org/licenses/by-nc-nd/4.0/.

\section{References}

1. Li H, Zheng RS, Zhang SW, et al. Analysis of breast cancer incidence and death among Chinese women in 2014. Chinese Journal of Oncology 2018;40:166-71.

2. Sun KX, Zheng RHS, Zhang SW, et al. Analysis of malignant tumor incidence and death by region in China in 2015. China Oncology 2019;28:1-11.

3. Allemani C, Matsuda T, Di Carlo V, et al. Global surveillance of trends in cancer survival 2000-14 (CONCORD-3): analysis of individual records for 37513025 patients diagnosed with one of 18 cancers from 322 population-based registries in 71 countries. Lancet 2018;391:1023-75.

4. Xing Y, Meng Q, Sun L, et al. Survival analysis of patients with unilateral and bilateral primary breast cancer in Northeast China. Breast Cancer 2015;22:536-43.

5. Zuo WS, Wang L. A brief review of the clinical practice of breast cancer surgery. A little reflection on the clinical practice of breast cancer surgery: A strategy for the clinical practice of localized breast surgery. Chinese Journal of Breast Diseases (electronic version) 2008;(1):1-12.

6. Zheng M, Lin H, Jiang ZC, et al. Breast-conserving surgery in 43 cases of breast cancer. Chinese Journal of Breast Diseases (electronic version) 2008;(2):214-9.

7. Litière $S$, Werutsky $G$, Fentiman IS, et al. Breast conserving therapy versus mastectomy for stage I-II breast cancer: 20 year follow-up of the EORTC 10801 phase 3 randomised trial. Lancet Oncol 2012;13:412-9.

8. Yu KD, Di GH, Wu J, et al. Development and trends of surgical modalities for breast cancer in China: a review of 16-year data. Ann Surg Oncol 2007;14:2502-9.

9. Veronesi U, Cascinelli N, Mariani L, et al. Twentyyear follow-up of a randomized study comparing breastconserving surgery with radical mastectomy for early breast cancer. N Engl J Med 2002;347:1227-32.

10. Veronesi U, Salvadori B, Luini A, et al. Breast conservation is a safe method in patients with small cancer of the breast. Long-term results of three randomised trials on 1,973 patients. Eur J Cancer 1995;31A:1574-9.

11. Bajaj AK, Kon PS, Oberg KC, et al. Aesthetic outcomes in patients undergoing breast conservation therapy for the treatment of localized breast cancer. Plast Reconstr Surg 2004;114:1442-9.

12. Wang HT, Barone CM, Steigelman MB, et al. Aesthetic outcomes in breast conservation therapy. Aesthet Surg J 2008;28:165-70.

13. Song EW, Gong C, Jin X. Basic research and clinical decision making in the precision treatment of breast cancer. Journal of Clinical Surgery 2016;24:653-5.

14. Jiang HC. Evaluation of surgical techniques and aesthetic results for breast cancer breast conservation and reconstruction. Chinese Journal of Practical Surgery 2011;31:961-3.

15. Tan M, Ung O. Alternative Approaches for Oncoplastic Breast Surgery. Ann Surg Oncol 2011;18:297-9.

16. Listed N. Delegations of authority and organization; Center for Devices and Radiological Health--FDA. Final rule. Federal Register 1994;59:27207.

17. Ma YB, Wang YM, Li W, et al. Application of areolar incision and residual cavity sutureless technique in the excision of benign breast masses. Chinese Journal of Aesthetic Medicine 2010;19:3-4.

18. Lassus C. A 30-Year Experience with Vertical Mammaplasty. Plast Reconstr Surg 1996;97:373-80.

19. Clough KB, Soussaline M, Campana F, et al. (Mammoplasty combined with irradiation: conservative treatment of breast cancer localized in the lower quadrant). Ann Chir Plast Esthet 1990;35:117-22.

20. Anderson BO, Masetti R, Silverstein MJ. Oncoplastic approaches to partial mastectomy: an overview of volumedisplacement techniques. Lancet Oncol 2005;6:145-57.

21. Benelli L. A new periareolar mammaplasty: the "round block" technique. Aesthetic Plast Surg 1990;14:93-100.

22. Wu K, Wang YS, Liu GY, et al. Expert consensus on breast-conserving treatment (2020 version). Chinese Journal of Cancer 2020;30:912-68.

23. Feißt M, Heil J, Stolpner I, et al. Psychometric validation 
of the Breast Cancer Treatment Outcome Scale

(BCTOS-12): a prospective cohort study. Arch Gynecol Obstet 2019;300:1679-86.

24. Audretsch W. Space-holding technic and immediate reconstruction of the female breast following subcutaneous and modified radical mastectomy. Arch Gynecol Obstet 1987;241 Suppl:S11-9.

25. Haloua MH, Krekel NM, Winters HA, et al. A systematic review of oncoplastic breast-conserving surgery: current weaknesses and future prospects. Ann Surg 2013;257:609-20.

26. Zhang BN, Shao ZM, Qiao XM, et al. A prospective multicenter study of breast-conserving treatment for breast cancer in China. Chinese Journal of Oncology 2005;(11):44-8.

27. Liu A, Wang H, Wang X, et al. Analysis of 10 cases of breast cancer preserving breast oncoplasty combined with simultaneous symmetrical breast reconstruction surgery on the healthy side. Chinese Journal of Breast Diseases (electronic version) 2015;9:127-33.

28. Yu ZH, Chang TJ, Qu Y, et al. Clinical application of plastic surgery techniques in breast-conserving surgery for early breast cancer. Medicine and Philosophy(B) 2016;37:51-2.

29. Down SK, Jha PK, Burger A, et al. Oncological advantages of oncoplastic breast-conserving surgery in treatment of early breast cancer. Breast J 2013;19:56-63.

30. Borger JH. The impact of surgical and pathological findings on radiotherapy of early breast cancer. Radiother Oncol 1991;22:230-6.

31. Vrieling C, Werkhoven E, Maingon P, et al. Prognostic factors for local control in breast cancer after longterm follow-up in the EORTC boost vs no boost trial: a randomized clinical trial. JAMA Oncol 2017;3:42-8.

32. Losken A, Dugal CS, Styblo TM, et al. A meta-analysis comparing breast conservation therapy alone to the oncoplastic technique. Ann Plast Surg 2014;72:145-9.

33. Pan YJ. Comparison of clinical efficacy of breastconserving surgery and modified radical surgery for earlystage breast cancer. China Medical Device Information 2017;23:108-9.

34. Zhou QL. Effect of humanistic care on postoperative psychological stress and self-care ability of patients undergoing modified radical mastectomy for breast cancer. Henan Medical Research 2020;29:2868-9.

35. Bao ZY, Wang K, Zhou L, et al. A controlled clinical study of breast-conserving surgery versus radical surgery for early breast cancer. Chinese General Medicine
2013;11:238-40.

36. Klassen AF, Pusic AL, Scott A, et al. Satisfaction and quality of life in women who undergo breast surgery: a qualitative study. BMC Womens Health 2009;9:11.

37. Kelsall JE, McCulley SJ, Brock L, et al. Comparing oncoplastic breast conserving surgery with mastectomy and immediate breast reconstruction: Case-matched patient reported outcomes. J Plast Reconstr Aesthet Surg 2017;70:1377-85.

38. Rosenberger LH, Mamtani A, Fuzesi S, et al. Early Adoption of the SSO-ASTRO Consensus Guidelines on Margins for Breast-Conserving Surgery with WholeBreast Irradiation in Stage I and II Invasive Breast Cancer: Initial Experience from Memorial Sloan Kettering Cancer Center. Ann Surg Oncol 2016;23:3239-46.

39. Clough KB, Kroll SS, Audretsch W. An Approach to the Repair of Partial Mastectomy Defects. Plast Reconstr Surg 1999;104:409-20.

40. Fisher B, Anderson S, Bryant J, et al. Twenty-year followup of a randomized trial comparing total mastectomy, lumpectomy, and lumpectomy plus irradiation for the treatment of invasive breast cancer. N Engl J Med 2002;347:1233-41.

41. Liu JL, Lan DY, Tang W, et al. Clinical Comparison of Breast Tumor Plastic Breast Conserving Surgery and Non-plastic Breast Conserving Surgery in the Treatment of Early Breast Cancer. Chinese Anti-Cancer Association 2014:434.

42. Gu JF, Li YH, Yi S. The effect of breast plastic surgery on the physical and mental health of patients with early breast cancer. Chinese and Foreign Medical Research 2020;18:39-41.

43. Garcia-Etienne CA, Tomatis M, Heil J, et al. Mastectomy trends for early-stage breast cancer: a report from the EUSOMA multi-institutional European database. Eur J Cancer 2012;48:1947-56.

44. Whelan TJ, Julian JA, Berrang TS, et al. External beam accelerated partial breast irradiation versus whole breast irradiation after breast conserving surgery in women with ductal carcinoma in situ and node-negative breast cancer (RAPID): a randomised controlled trial. Lancet 2019;394:2165-72.

45. Correa C, Harris E, Leonardi MC, et al. Accelerated partial breast irradiation: executive summary for the update of an ASTRO evidence-based consensus statement. Pract Radiat Oncol 2017;7:73-9.

46. Smith BD, Arthur DW, Buchholz TA, et al. Accelerated partial breast irradiation consensus statement from the 
American Society for Radiation Oncology (ASTRO). Int J Radiat Oncol Biol Phys 2009;74:987-1001.

47. Cabioglu N, Hunt KK, Sahin A, et al. Role for intraoperative margin assessment in patients

Cite this article as: Huang S, Qiu P, Li J, Liang Z, Yan Z, Luo K, Huang B, Yu L, Chen W, Zhang Y. Strategies for the selection of oncoplastic techniques in the treatment of earlystage breast cancer patients. Gland Surg 2021;10(5):1687-1700. doi: $10.21037 / g s-21-212$ undergoing breast-conserving surgery. Ann Surg Oncol 2007;14:1458-71.

(English Language Editor: J. Teoh) 